\title{
Synergistic effects of combined curcumin and antibiotic in ameliorating an animal model of Helicobacter pylori infection.
}

\author{
Reza Ranjbar*, Atabak Mohammadi \\ Molecular Biology Research Center, Systems Biology and Poisonings Institute, Baqiyatallah University of Medical \\ Sciences, Tehran, Iran
}

\begin{abstract}
Introduction: Helicobacter pylori is a Gram-negative, moving, helix-shaped and Microaerophilic bacterium which infects the human's stomach in childhood and stays for a long time. Helicobacter pylori is a gastrointestinal pathogen in human body and causes chronic and active stomach inflammation as well as gastrointestinal ulcers. The purpose of this study is to investigate the effects of curcumin on Helicobacter pylori in the mice model.

Material and Methods: In this study, after induction of Helicobacter pylori disease to the Balb/c mice, we started to treat different groups of mice in the second week of sicknesses using oral administration of curcumin, common antibiotics in curing Helicobacter pylori, and antibiotics with curcumin. One group received no treatment as a negative control group and the other group received Helicobacter pylori without any treatment as a positive control group. Oral prescriptions were conducted within 15 days and blood sampling was then carried out from the mice hearts. The rate of anti-Helicobacter pylori antibodies was then calculated in serum and then, urea tests were done on the mice stomach.

Results: Results revealed that the effectiveness of Curcumin in rate is less than the antibiotic group but decreased the amount of Helicobacter pylori infection compared to the infected host group. Combined therapy had synergistic effects and caused a more significant reduction in gastrin, IFN- $\gamma$, MPO activity and lipid peroxidation compared to mice receiving each monotherapy.

Conclusion: It seems that Curcumin, as a natural complex without any side effects, will receive enough attention in inhibiting the infection proliferation.
\end{abstract}

Keywords: Helicobacter pylori, Curcumin, Balb/c mice.

Accepted on March 02, 2018

\section{Introduction}

Gastrointestinal ulcers or in scientific terms "Ulcer Peptic" had affected humans for centuries and its cause was not clear until recently. In the 1940's, Dr. A. Stone Freedberg from Harvard Medical University found an unusual spiral bacterium in the stomach of the people with Ulcer Peptic [1,2]. Helicobacter pylori is a gram-negative and spiral bacterium. It also contains urease, catalase, and oxidase which plays a significant role in the pathogenesis of gastritis, peptic ulcers, and neoplasia. Considering its virulence factors (pathogenic factors), which include Urease, moving flagella, adhesion and VacA and Cag A vacuolating Cytotoxins, this bacterium sticks to gastric and duodenal mucosal surface of the stomach and bothers them [1-4]. The proliferation of the mucus of the stomach and duodenal increases the danger of gastric and duodenal ulcer stomach adenocarcinoma. Cag secretion system is the most important virulent factor related to stomach adenocarcinoma. Although Helicobacter pylori was identified and recognized about 20 years ago [2], more than half of the population of the world have been infected to this disease nowadays and about 50000 of annual deaths in the world is because of stomach cancer which are related to Helicobacter pylori. Therefore, early detection of Helicobacter pylori is of significant importance [5-7].

Helicobacter pylori contamination is higher in developing countries particularly those with lower ages. In these countries, the incidence of infection by age 10 is $60-50 \%$, and in adults is more than $90 \%$ [8]. Several reports have been made concerning the negative impact of Helicobacter pylori infection on the development of the children indicating a daily increase in the number [9]. Turmeric is a medical plant which is widely used as edible seasoning from its rhizome. Rhizome extract is called curcuminoid and it includes curcumin, dimetixocorquine and dimetixine curcumin base [10]. Curcumin is insoluble in water and ether but dissolves in alcohol, acetic acid, alkaline and some oils, including olive oil. Due to its many properties in biological systems, extensive research has been made on it. As it can be seen, antioxidant and antioxidant effects have been shown to inhibit 5-lipoxygenase and reduced levels of cytokines such as TNF- $\alpha$, IL-1 $\beta$, and interferon-gamma [11]. Curcumin also has an inhibitory effect on apoptosis with TGF$\beta$ and Caspase-3. Various studies have shown that curcumin 
has protective effects against functional disorders, tissue damage, oxidative stress, and inflammation associated with ischemia. According to recent reports, oral administration of curcumin has significantly reduced pro-inflammatory factors as well as apoptosis in renal tissue following ischemic/rehepatoplasty and also showed that pretreatment with curcumin reduced tissue damage and inflammation of the kidneys following half an hour of ischemia and $24 \mathrm{~h}$ of re-blood transfusion in mice. Recently, clinical applications have also been reported for curcumin. Some of the most important diseases in which curcumin is being used against are rheumatoid arthritis, post-surgical inflammation, idiopathic orbit inflammation, Alzheimer's disease and multiple myeloma, and pancreatic and colon cancers [12,13]. The present study was organized regarding the mentioned cases, and considering that no studies have been done on the effects of curcumin on the improvement of symptoms and reduction of Helicobacter pylori survival.

\section{Materials and Methods}

This study is considered to be an experimental study. It consists of $50 \mathrm{Balb} / \mathrm{c}$ mice which were randomly divided into 5 groups of 10. Helicobacter pylori strains were isolated from Iranian patients with gastrointestinal disorders who referred to endoscopic centers. The strains were cultured on Brucella-agar plates containing 7-5\% sheep blood and related antibiotics and heated under microwave oven conditions at $37^{\circ} \mathrm{C}$ for 7 to 5 days. The isolated Helicobacter pylori strains were identified based on colony forms, hot staining, urease production, catalase, and oxidase enzymes. Plates containing Helicobacter pylori were diluted, washed, and inoculated into three doses containing $\mathrm{CFU} 10^{9}$ into the stomach of rats through polyethylene tubes. Two weeks after the infection, rats were treated with curcumin and antibiotics for 2 weeks. Then, in the fifth week, the mice were subjected to blood sampling for serum isolation to determine $\operatorname{IgG}$ and $\operatorname{IgM}$ antibodies against Helicobacter pylori and then, they died of spinal cord injury and several biopsies were conducted in the stomach of controlled ones, infected ones and the treated ones and were evaluated to determine the presence of bacteria through rapid test of urease and cyst.

For rats with positive urease test, the tissue culture was performed. The experimental design and study groups were as follows:

Group 1 (negative control): 10 healthy mice that received oral PBS buffer from the third week of the study for 2 weeks.

Group 2 (positive control): Included 10 mice that Helicobacter pylori was transferred to their stomach through the gavage tube and received PBS buffer from the third week of the study for 2 weeks.

Group 3 (treated with curcumin): 10 mice that Helicobacter pylori was transferred to their stomach through the gavage tube and then received $200 \mathrm{mg} / \mathrm{kg}$ curcumin through oral administration from the third week of the study for 2 weeks daily.
Group 4 (treated with antibiotic): Included 10 mice that Helicobacter pylori was transferred to their stomach through the gavage tube and from the third week of the study for 2 weeks with daily oral gavage of a combination of antibiotics (metronidazole: 8 micrograms per gram of mouse weight, erythromycin: $16 \mu \mathrm{g}$ per gram of mouse weight, bismuth substrate: $8 \mu \mathrm{g}$ per gram of mouse weight).

Group 5 (treated with curcumin+antibiotic): Included 10 mice that Helicobacter pylori was transferred to their stomach through the gavage tube. From the third week rats received 200 $\mathrm{mg} / \mathrm{kg}$ of curcumin through oral administration and combination of antibiotics (metronidazole: 8 micrograms per gram of mouse weight, erythromycin: $16 \mu \mathrm{g}$ per gram of mouse weight, bismuth substrate: $8 \mu \mathrm{g}$ per gram of mouse weight) daily for 2 weeks.

\section{ELISA assay}

The serum samples of the animal were collected and the levels of IFN- $\gamma$, IL-4, somatostatin, and gastrin were determined by ELISA according to the manufacturer's instructions [11].

\section{Lipid peroxide level in the gastric mucosal tissues}

Gastric mucosal tissues were scrapped and homogenized in 10 $\mathrm{mmol} / \mathrm{L}$ Tris buffer ( $\mathrm{pH}$ 7.4). Lipid peroxide levels were measured based on a thiobarbituric acid assay as previously demonstrated [14].

\section{Evaluation of MPO activity in the gastric mucosal tissues}

Briefly, $10 \mu \mathrm{l}$ of homogenized gastric mucosal tissues were mixed with $80 \mu \mathrm{l}$ of $0.75 \mathrm{mM} \mathrm{H}_{2} \mathrm{O}_{2}$ and $110 \mu \mathrm{TMB}$ solution (2.9 mM TMB in 14.5\% DMSO plus $150 \mathrm{mM}$ sodium phosphate buffer at $\mathrm{pH}$ 5.4). Samples were incubated at $37^{\circ} \mathrm{C}$ for $5 \mathrm{~min}$. Next, for termination of the reaction, $50 \mu \mathrm{l}$ of $2 \mathrm{M}$ $\mathrm{H}_{2} \mathrm{SO}_{4}$ was added and the absorbance was determined spectrophotometrically at $450 \mathrm{~nm}$ [15].

\section{Data analysis method}

SPSS21 software and one-way ANOVA were used for statistical analysis of data and Excel software was used for plotting the graphs of means $\pm \mathrm{SD} . \mathrm{P}<0.05$ was considered as a significant level.

\section{Results}

After two weeks of treatment with $H$. pylori, anti- $H$. pylori antibodies were measured in rats. The results showed that the amount of anti- $H$. pylori antibody was increased in all groups, compared to the negative group. The treatment with curcumin and antibiotics don't have significant change $(p>0.05)$ on antibody titer $(\operatorname{IgM})$ compared to the positive group, but in the combined treatment group (curcumin and antibiotics treatment), amount of IgM significantly decreased $(\mathrm{p}<0.05)$ compared to the treatments in positive group (Figure 1A). Also the amount of IgG titer significantly decreased $(\mathrm{p}<0.05)$ in 
curcumin, antibody and curcumin + antibody groups compared to the positive group (Figure 1B).
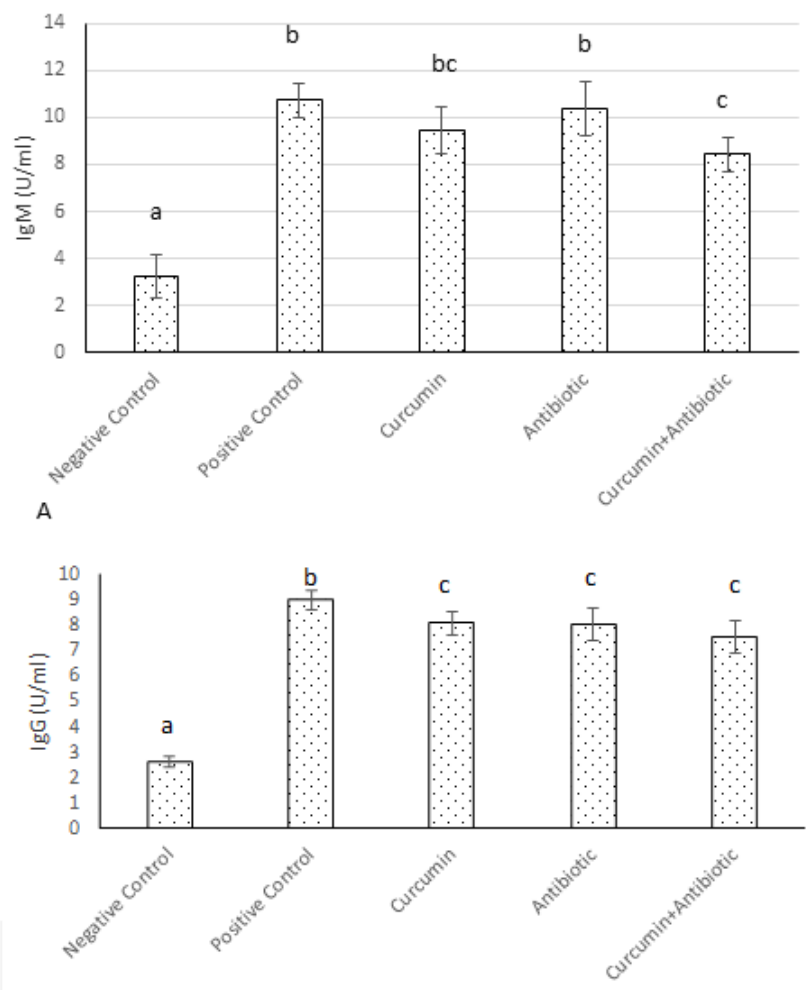

B

Figure 1. A) Amount of IgM and B) IgG antibody produced against Helicobacter Pylori. Significant statistical differences between groups in each index are indicated by the different superscript letter $(p<0.05)$.

ELISA assay showed that the levels of IFN- $\gamma$, gastrin, Somatostatin and IL-4 were significantly increased in positive control group compared to the negative control ones (Figures 2A-2D). The treated group had the lower level of IFN- $\gamma$ compared to the positive group $(\mathrm{p}<0.05)$. The significant difference was between treated groups, whereas curcumin + antibiotic group, had the lowest level of IFN- $\gamma$ than antibiotic and curcumin group (Figure $2 \mathrm{~A} ; \mathrm{p}<0.05$ ). The somatostatin levels in curcumin and antibiotic treatment group did not show significant difference comparing to the positive group, but combined treatment group (curcumin+antibiotic), had a significant decrease $(p>0.05)$ in somatostatin levels compared to the curcumin and antibiotic group and positive group (Figure 2B). The gastrin levels in treatment groups that received Curcumin, Antibiotic and combined treatment (curcumin+antibiotic) showed significant decrease $(p<0.05)$ compared to the positive group. The significant difference was shown between treated groups, whereas curcumin+antibiotic, antibiotic and curcumin group had the lowest level of gastrin respectively (Figure 2C). Treatment group received Curcumin or Antibiotic, each alone or in combination, and showed a significant increase $(p<0.05)$ in the levels of IL-4 compared to the positive control group (Figure 2D), although, the level of IL-4 was significantly up-regulated in combination therapy which were more profound than the levels in each therapy alone (Figure 2D).
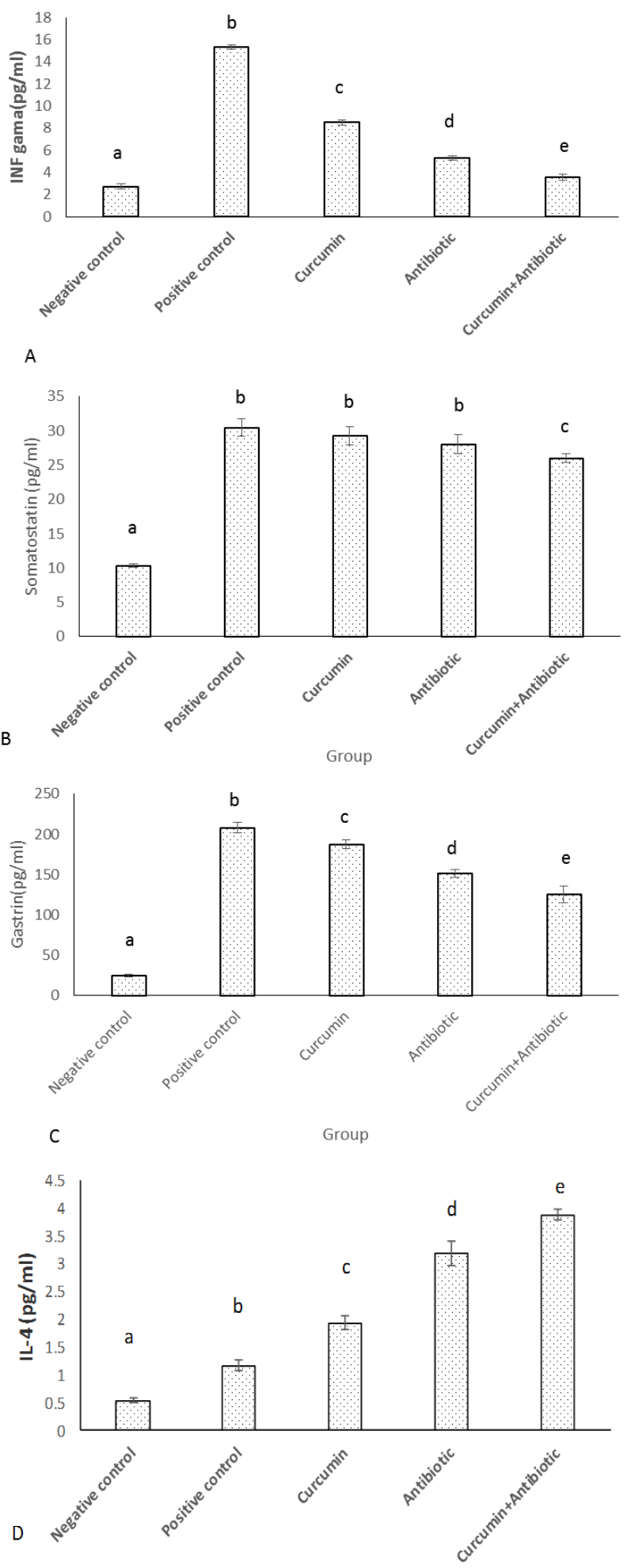

Figure 2. A) Amount of INF- $\gamma$; B) Somatostatin; C) Gastrin; D) IL-4 produced in serum. Significant statistical differences between groups in each index are indicated by the different superscript letter $(p<0.05)$.

Results of MPO and LPO measurement indicated that MPO activity and lipid peroxidation were significantly increased 
$(p<0.05)$ in positive control group compared to negative ones. Antibiotic, curcumin (with less intensity) and curcumin +antibiotic therapy could significantly decrease $(p<0.05)$ these items than the positive group. Although combined therapy has synergistic effects and caused more significant suppression in the levels of MPO activity and lipid peroxidation (LPO) compared to mice that each received monotherapy (Figures 3 and 4).

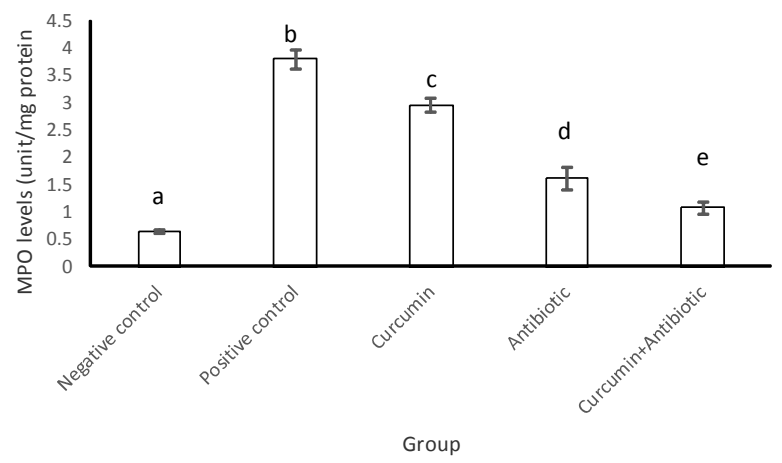

Figure 3. Amount of MPO produced in serum. Significant statistical differences between groups in each index are indicated by the different superscript letter $(p<0.05)$.

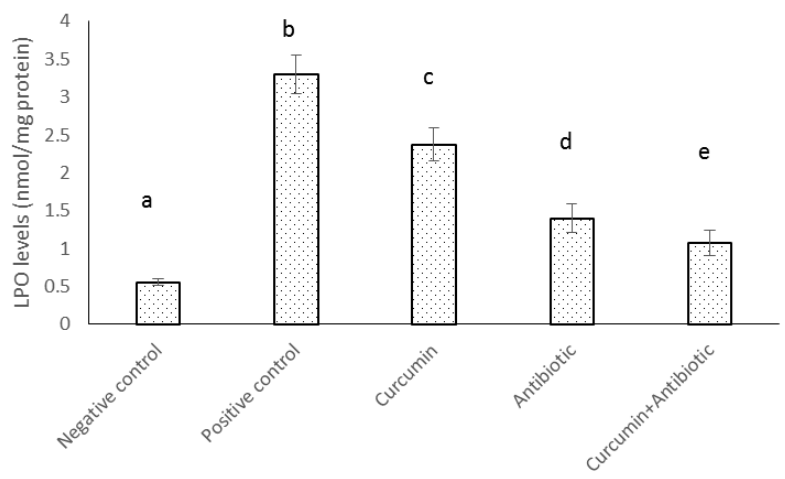

Figure 4. Amount of LPO produced in serum. Significant statistical differences between groups in each index are indicated by the different superscript letter $(p<0.05)$.

\section{Discussion}

The presence of microbial agents in the stomach was discovered about 100 years ago, but since the 1970's its association with gastritis (gastric mucosal inflammation) was diagnosed [16]. The prevalence of Helicobacter pylori infection was $50 \%$ to $80 \%$ respectively in developed and developing countries. Also, the rate of infection of this bacterium in different provinces of Iran had a high percentage. Based on research conducted in Shiraz, the rate of Helicobacter pylori infection was 98\% among two-year-old children, 89\% among 10-year-old children and 57\% among 15 year-old adolescents. The prevalence of this disease was $47 \%$ in Ardabil province, $30 \%$ in Yazd and 52\% in Zanjan, among the ages of 7-9. In Tehran, the prevalence of Helicobacter pylori infection in cases of ulcer, gastritis, and duodenitis was $96 \%, 80 \%$, and $50 \%$, respectively, and prevalence in normal endoscopy was $75 \%$ [17]. Since the discovery of Helicobacter pylori, several studies found the association between this bacteria and gastrointestinal, gastric and duodenal ulcers. It is also related to the emergence of cynomolgus and stomach lymphoma. Several studies had examined the role of Helicobacter pylori as a potential risk factor for coronary arteries [18]. In Iran, several studies have been done on the role of this bacterium and the incidence of atherosclerosis, gallstones, and indigestion, and further studies have been done on the role of Helicobacter pylori in the metabolic syndrome, as well as type I diabetes and insulin resistance [19].

Several drugs were evaluated for the treatment of Helicobacter pylori infection, and no drug alone was effective in treating this micro-organism. What is considered appropriate for Helicobacter pylori treatment in metronidazole triple therapy, tetracycline and bismuth, which is not costly, but has a series of side effects such as oral metallic taste due to metronidazole and increased sensitivity to light in the effect taking tetracycline and other complications such as gray-colored intermittent oral and dental pains, constipation, diarrhea and stool colon [18-20]. Several studies carried out in various fields such as biotechnology, pharmacognosy, drug chemistry and etc., in order to find new drugs to influence on this infection, among which special attention has been paid to medicinal plants. One of these medicinal plants is turmeric. It has been used in ancient Asian medicine for the treatment of skin diseases and wound healing. For example, in India, it was rubbed on infectious wounds and healed it by destroying the bacterial wounds. In new medicine, turmeric, anti-bacterial, antifungal, antimicrobial and antiviral effects have been reported [21]. For example, its alcoholic extract was effective on gram-positive bacterium in vitro. Turmeric strongly affects Salmonella but is not effective on $E$. coli [22]. It has been reported in the study that the active ingredient (curcumin) of this plant is effective on the HIV virus, where selected drugs have not been effective for this disease. There are also reports on the effect of Turmeric ether and Ethel on Staphylococcus and Klebsiella pneumonia [22-24].

Regarding the cases mentioned above, the present study examined the antimicrobial activity of the active ingredient of Choba plant (Curcumin) on induced Helicobacter pylori bacteria in the stomach of C57/b16 mice. The results of our study showed that anti-Helicobacter pylori antibodies were increased in the serum of mice following induction of disease, which was not significantly decreased with curcumin and antibiotics. Meanwhile, in the healthy group, anti-Helicobacter pylori antibodies were negative. Accordingly, rapid urease test that was performed on gastric mucosal samples compared to antibiotics, has less anti-proliferative ability on Helicobacter pylori. Although it reduces Helicobacter pylori disease in mice, the recipient was curcumin, and it could recommend that this active ingredient is used in combination with antibiotics in patients with Helicobacter pylori.

In a study by Tyagi et al. entitled "Anti-bacterial effects of curcumin on bacterial membrane damage" they reported that the antioxidant effects on gram-positive bacteria, including 
Staphylococcus aureus and Enterococcus feces, and also Gramnegative bacteria including Pseudomonas aerogenosa and Ocala, which are important human pathogens, inhibit their growth, and eventually suggested that the antibiotic potential of curcumin should be studied further [25]. In the recently study in Turkey, Hayatay et al. reviewed the extent of curcumin inhibition with common antibiotics in bacterial infections. They showed that curcumin should be used at high concentrations in order to maintain its inhibitory strength by inhibiting other antibiotics [26]. Kali et al. reported that curcumin had an inhibitory effect on biofilm-producing bacteria when used with antibiotics. They also stated that the use of this substance would be beneficial in antibiotic therapy [27]. In their, other study named Anti-bacterial effects of curcumin on bacteria that contaminated the mouth, Njaah et al. reported that curcumin is effective in preventing decay and biofilm formation, and it is useful to consider it as an alternative method. The results of our study were also in line with the above studies [28].

Because of participation of free radicals in the pathogenesis of Helicobacter gastritis, eliminating these causal inflammatory triggers may be a useful strategy. Interestingly, it is clear that the curcumin possesses antioxidant properties [29]. The levels of lipid peroxidation, an oxidative damage index, and MPO activity, among factors causing the lipid peroxidation, were decreased by the treatment with combined curcumin and erythromycin. In some cases, it almost reached the levels found in non-infected animals. Therefore, some of the beneficial effects reported in combination therapy may be due to the potent antioxidant properties of curcumin. ELISA assays were performed to investigate the mechanism of synergistic benefits of combined therapy. Similar to current result, it has been reported that the levels of IFN- $\gamma$ as a potent inflammatory cytokine was increased by $H$. pylori infection [30]. Attained data showed that curcumin (by direct anti-inflammatory and anti-microbial effects) and erythromycin (by decreasing the agent's induced inflammation), could regress the levels of cytokine. More importantly, combined therapy has synergistic beneficial effects in decreasing cytokine.

IL-4 is a prominent anti-inflammatory cytokine. It is reported that the production IL-4 is suppressed by $H$. pylori [31]. On the other hand, somatostatin is a regulatory hormone needed for IL-4 mediated resolution of $H$. pylori-related [32]. A significant benefit of combined therapy on IL-4 more profound than single therapy alone suggested that combined therapy could reduce the effects of $H$. pylori infection more than each therapy alone. Gastrin is a hormone produced by $\mathrm{G}$ cells from the antrum and involved in the production of gastric acid [33]. Similar to current result, it is clear the levels of gastrin and gastric acid were increased by $\mathrm{H}$. pylori infection. Our results showed that combined therapy could reduce production of gastrin more profound than each monotherapy alone.

\section{Conclusion}

According to previous studies, the result of this study suggested that curcumin, as a natural compound in the treatment of Helicobacter pylori infection, could be considered in pharmacological, clinical and industrial studies of curcumin in various forms of medication including oral selected antibiotics which were used to treat patients with Helicobacter pylori infections. Moreover, combined curcumin and antibiotic therapy had the beneficial synergistic effect to control Helicobacter pylori infections.

\section{Acknowledgment}

We would like to thank from the "Clinical Research Development Center of Baqiyatallah hospital" for their kindly cooperation. This study was financially supported in part by "Clinical Research Development Center of Baqiyatallah hospital"

\section{References}

1. Ranjbar R, Behzadi P, Farshad S. Advances in diagnosis and treatment of Helicobacter pylori infection. Acta Microbiol Immunol Hung 2017; 6: 1-20.

2. Ranjbar R, Khamesipour F, Jonaidi-Jafari N, Rahimi E. Helicobacter pylori in bottled mineral water: genotyping and antimicrobial resistance properties. BMC Microbiol 2016; 16: 40.

3. Kargar M, Ghorbani-Dalini S, Doosti A, Souod N. RealTime PCR assay using Allele-Specific TaqMan probe for detection of clarithromycin resistance and its point mutations in Helicobacter pylori. J Isfahan Medical School 2011; 29: 65-73.

4. Izadi M, Fazel M, Sharubandi SH, Saadat SH, Farahani MM, Nasseri MH, Dabiri H, SafiAryan R, Esfahani AA, Ahmadi A, Jonaidi Jafari N, Ranjbar R, JamaliMoghaddam SR, Kazemi-Saleh D, Kalantar-Motamed MH, Taheri S. Helicobacter species in the atherosclerotic plaques of patients with coronary artery disease. Cardiovasc Pathol 2012; 21: 307-311.

5. Izadi M, Fazel M, Karbasi-Afshar R, Saadat SH, Nasseri $\mathrm{MH}$, Jonaidi-Jafari N, Ranjbar R, Kazemi-Saleh D. Glycemic control in type 2 diabetes mellitus prevents coronary arterial wall infection. ARYA Atheroscler 2014; 10: 141-146.

6. Farshad S, Alborzi A, Japoni A, Ranjbar R, Hosseini Asl K, Badiee P, Amin Shahidi M, Hosseini M. Antimicrobial susceptibility of Helicobacter pylori strains isolated from patients in Shiraz, Southern Iran. World J Gastroenterol 2010; 16: 5746-5751.

7. Ghasemi A, Shirazi MH, Ranjbar R, Khorramizadeh MR, Daryani NE, Hosseini M. The prevalence of cagA and cagE genes in Helicobacter pylori strains isolated from different patient groups by polymerase chain reaction. Pak J Biol Sci 2008; 15: 2579-2583.

8. Farshad S, Rasouli M, Jamshidzadeh A, Hosseinkhani A, Japoni A, Alborzi A, Taghavi A, Kazemi Asl H, Ranjbar R. IL-1ß $\quad(+3953 \quad \mathrm{C} / \mathrm{T})$ and IL-8 $\quad(-251 \quad \mathrm{~A} / \mathrm{T})$ gene polymorphisms in $\mathrm{H}$. pylori mediated gastric disorders. Iran J Immunol 2011; 7: 96-108. 
9. Pakbaz Z, Shirazi MH, Ranjbar R, Pourmand MR, Khalifeh Gholi M, Aliramezani A, Vaise Malekshahi Z. Frequency of sabA Gene in Helicobacter pylori Strains Isolated From Patients in Tehran, Iran. Iran Red Crescent Med J 2013; 15: 767-770.

10. Youn GS, Kwon DJ, Ju SM, Choi SY, Park J. Curcumin ameliorates TNF-a-induced ICAM-1 expression and subsequent THP-1 adhesiveness via the induction of heme oxygenase-1 in the HaCaT cells. BMC Rep 2013; 46: 410-415.

11. Sreejayan, Rao MN. Curcuminoids as potent inhibitors of lipid peroxidation. J Pharm Pharmacol 1994; 46: 1013-1016.

12. Zhou H, Beevers CS, Huang S. The targets of curcumin. Curr Drug Targets 2011; 12: 332-347.

13. Jayaprakasha GK, Jagan Mohan Rao L, Sakariah KK. Improved HPLC method for the determination of curcumin, demethoxycurcumin, and bisdemethoxycurcumin. J Agric Food Chem 2002; 50: 3668-3672.

14. Janero DR. Malondialdehyde and thiobarbituric acidreactivity as diagnostic indices of lipid peroxidation and peroxidative tissue injury. Free Radic Biol Med 1990; 9: 515-540.

15. Pulli B, Ali M, Forghani R, Schob S, Hsieh KL, Wojtkiewicz G, Linnoila JJ, Chen JW. Measuring myeloperoxidase activity in biological samples. PLoS One 2013; 8: e67976.

16. Mousavi S, Safarpoor Dehkordi F, Rahimi E. Virulence factors and antibiotic resistance of Helicobacter pylori isolated from raw milk and unpasteurized dairy products in Iran. J Venom Anim Toxins Incl Trop Dis 2014; 20: 51.

17. Shokrzadeh L, Alebouyeh M, Mirzaei T, Farzi N and Zali MR. Prevalence of multiple drug-resistant Helicobacter pylori strains among patients with different gastric disorders in Iran. Microb Drug Resist 2015; 21: 105-110.

18. Bahrami AR, Rahimi E, Ghasemian Safaei H. Detection of Helicobacter pylori in city water, dental units' water, and bottled mineral water in Isfahan, Iran. Sci World J Article 2013; 55: 274-289.

19. Mirzaei N, Poursina F, Faghri J, Talebi M, Khataminezhad MR, Hasanzadeh A, Ghasemian Safaei H. Prevalence of resistance to Helicobacter pylori strains to selected antibiotics in Isfahan, Iran. Jundishapur J Microbiol 2013; 6: e6342.

20. Havaei SA, Mohajeri P, Khashei R, Salehi R, Tavakoli H. Prevalence of Helicobacter pylori vacA different genotypes in Isfahan, Iran. Adv Biomed Res 2014; 3: 48.

21. Zeng C, Zhong P, Zhao Y, Kanchana K, Zhang Y, Khan ZA, Chakrabarti S, Wu L, Wang J, Liang G. Curcumin protects hearts from FFA-induced injury by activating Nrf2 and inactivating NF-kappaB bothin vitro and in vivo. $\mathrm{J} \mathrm{Mol}$ Cell Cardiol 2015.

22. Vera-Ramirez L, Pérez-Lopez P, Varela-Lopez A, RamirezTortosa M, Battino M, Quiles JL. Curcumin and liver disease. Biofactors 2013; 39: 88-100.
23. Brondino N, Re S, Boldrini A, Cuccomarino A, Lanati N, Barale F, Politi P. Curcumin as a therapeutic agent in dementia: A mini systematic review of human studies. Sci World J 2014.

24. Hosseinzadeh M, Khosravi A, Saki K, Ranjbar R. Evaluation of Helicobacter pylori infection in patients with common migraine headache. Arch Med Sci 2011; 7: 844-849.

25. Tyagi P, Singh M, Kumari H, Kumari A, Mukhopadhyay K. Bactericidal activity of curcumin I is associated with damaging of bacterial membrane. PLoS ONE 2015; 10: $\mathrm{e} 0121313$.

26. Hayati G, Dumrul G, Reyhan M, Abdullah G, Tekin T, Aynur ET. Antibacterial effects of curcumin: an in vitro minimum inhibitory concentration study. Toxicol Indust Health 2013.

27. Kali A, Bhuvaneshwar D, Charles PM, Seetha KS. Antibacterial synergy of curcumin with antibiotics against biofilm producing clinical bacterial isolates. J Basic Clin Pharma 2016; 7: 93-96.

28. Najah AM, Neama YH. Evaluation of antimicrobial activity of curcumin against two oral bacteria. Autom Contr Intel Sys Artific Nano Sens Sys 2015; 3: 18-21.

29. Menon VP, Sudheer AR. Antioxidant and antiinflammatory properties of curcumin. Adv Exp Med Biol 2007; 595: 105-125.

30. Wang YC, Chen CL, Sheu BS. Helicobacter pylori infection activates Src homology-2 domain-containing phosphatase 2 to suppress IFN-? signaling. J Immunol 2014; 193: 4149-4158.

31. Karttunen R, Karttunen T, Ekre HP. Interferon gamma and interleukin 4 secreting cells in the gastric antrum in Helicobacter pylori positive and negative gastritis. Gut 1995; 36: 341-345.

32. Kao JY, Pierzchala A, Rathinavelu S, Zavros Y, Tessier A, Merchant JL. Somatostatin inhibits dendritic cell responsiveness to Helicobacter pylori. Regul Pept 2006; 134: 23-29.

33. Park SM, Lee HR, Kim JG, Park JW, Jung G, Han SH, Cho JH, Kim MK. Effect of Helicobacter pylori infection on antral gastrin and somatostatin cells and on serum gastrin concentrations. Korean J Intern Med 1999; 14: 15-20.

\section{*Correspondence to}

Reza Ranjabar

Molecular Biology Research Center

Systems Biology and Poisonings Institute

Baqiyatallah University of Medical Sciences

Iran 